\title{
Russian Federation: mental healthcare and reform
}

\section{Valery Krasnov, ${ }^{1}$ Isaak Gurovich ${ }^{2}$ and Alexey Bobrov ${ }^{3}$}

'Director, and Head of Department of Affective Spectrum Disorders, Moscow Research Institute of Psychiatry, Russia email krasnov@mtu-net.ru

2Deputy Director, and Head of Department of Organisation of Mental Healthcare, Moscow Research Institute of Psychiatry ${ }^{3}$ Deputy Director for Education, Moscow Research Institute of Psychiatry

$T^{\text {the }}$ he Russian Federation is a country with an enormous territory, of over 17 million $\mathrm{km}^{2}$. Its population is 141.9 million (2010 figure). The population was declining, especially at the end of the 1990s, but in more recent years the tendency has been towards stabilisation. Life expectancy has remained relatively low, although it has increased somewhat over the past few years, to reach 67.5 years in 2008 (61.4 for men and 73.9 for women), up from 65.3 years in 2004 (58.9 for men and 72.3 for women).

The budget for healthcare has remained low compared with that in other countries, both high-income and low- and middle-income ones, and constituted in 2009 about 5.5\% of gross national product (GNP). However, it should be mentioned that the federal allocations during the same period had grown from $2.3 \%$ to $3.5 \%$ of GNP; the rest of the total budget was provided by the state medical insurance system. There are significant differences between different regions in the financial support for local healthcare from municipal budgets. Psychiatric care is financed from the federal budget and is not included in the state medical insurance system.

\section{Psychiatric care}

In general, the psychiatric care system is based on two main types of facility: the territorial psychiatric out-patient clinics, termed 'dispensaries' (in rural areas these are units located by general hospitals), which provide care for the population residing in a specific territory; and the psychiatric hospitals, which generally provide in-patient treatment for the population within a certain catchment area (district, city or region). As a rule, a dispensary district psychiatrist provides care for an adult catchment population of around 25000, whereas child psychiatrists (who usually work in a child territorial polyclinic) provide care for a catchment population of 15000 children and adolescents. These figures, though, will adjusted for territories with a lower population density.

Psychiatric dispensaries may additionally provide specialist services such as psychotherapy, neurology, epileptology, sexology and gerontopsychiatry; they may also set up day hospitals. So-called 'narcology' services for people with alcohol and drug addiction were established in Soviet times, and until now they have mostly operated separately from regular mental health services.

A specific feature and principal defect of in-patient psychiatric care in Russia is its over-centralisation. The majority of psychiatric hospitals have more than 500 beds and some more than 1500. Nevertheless, over the past few decades the total number of beds has decreased by $25 \%$ and this process is continuing gradually. However, the decrease in psychiatric bed numbers has not always been accompanied by an increase in the provision of extramural forms of psychiatric care (Table 1).

The system of psychiatric care has shown contradictory tendencies in its development. On the one hand, taking into account the shortages in state budget allocations, psychiatric care on the basis of local psychiatric dispensaries that are open to the general public and connected to local psychiatric hospitals is expedient. On the other hand, psychiatric patients' stigma and societal prejudices against psychiatry and psychiatric institutions hinder the development of psychiatric dispensaries.

Only about 30-35\% of all patients with a mental illness apply for psychiatric assistance in the dispensary. However, recently the number of patients asking for an initial psychiatric consultation has started to increase. The prevalence of mental disorders registered in psychiatric institutions has reached 2978.7 per 100000 population (Table 2). At the same time, the problem of mental disorders in primary care is becoming more and more serious, such that, at present, some $25-30 \%$ of primary care patients need a psychiatric consultation. The need has arisen to reform and develop outpatient psychiatric care.

Table 1 Extent of psychiatric care resources

\begin{tabular}{|c|c|c|}
\hline Mental health resource, $n$ & 1999 & 2008 \\
\hline Psychiatric dispensaries & 164 & 145 \\
\hline $\begin{array}{l}\text { Dispensary departments in psychiatric } \\
\text { hospitals }\end{array}$ & 122 & 123 \\
\hline $\begin{array}{l}\text { Narcological dispensaries (for people } \\
\text { with alcohol and drug addiction) }\end{array}$ & 171 & 144 \\
\hline $\begin{array}{l}\text { Dispensary units in general hospitals } \\
\text { (in rural areas) }\end{array}$ & 2322 & 2078 \\
\hline $\begin{array}{l}\text { Psychotherapeutic units in general } \\
\text { out-patient clinics }\end{array}$ & 1118 & 1107 \\
\hline Psychiatric hospitals & 278 & 257 \\
\hline Narcological hospitals & 13 & 12 \\
\hline $\begin{array}{l}\text { In-patient departments in psychiatric } \\
\text { dispensaries }\end{array}$ & 107 & 88 \\
\hline $\begin{array}{l}\text { Total psychiatric beds (in psychiatric plus } \\
\text { general hospitals) }\end{array}$ & 170440 & 155834 \\
\hline $\begin{array}{l}\text { Total beds in general hospitals (included } \\
\text { in total above) }\end{array}$ & 14015 & 13890 \\
\hline Total beds in narcological hospitals & 28700 & 26550 \\
\hline Total places in day hospitals & 13645 & 17289 \\
\hline
\end{tabular}


Table 2 Patient populations

\begin{tabular}{|lrr|}
\hline Patient population, $n$ & 1999 & 2008 \\
\hline $\begin{array}{l}\text { Persons with mental disorders } \\
\text { (without substance misuse) }\end{array}$ & 3813500 & 4226899 \\
$\begin{array}{l}\text { Persons with alcohol misuse } \\
\text { Persons with drug addiction }\end{array}$ & 2230050 & 2728010 \\
\hline
\end{tabular}

National data from state psychiatric and narcological dispensaries and psychotherapeutic units.

The suicide rate in Russia is one of the highest in the world, although in recent years it has decreased slightly, from 38.7 per 100000 in 1999 to 27.1 in 2008 . The figure for men is six times higher than that for women, which may be related to greater alcohol consumption among men. Alcohol consumption in Russia is approximately 14-15 litres per capita (Nemtsov, 2009). The prevalence of alcoholism, including alcohol psychoses, has been more or less stable over the past decade, but with a slight tendency to increase, up to 1922.4 per 100000 population in 2008; the male:female ratio was 5:1 (Koshkin, 2009; see also Table 2). Addiction to other substances has also apparently increased in recent years. The prevalence rate was 252.2 per 100000 in 2008 (Koshkina, 2009). Opioid dependence accounted for $87.5 \%$ of this group.

Over the past few years, the total number of people with a mental illness who are registered disabled has increased by 20\%, and in 2008 reached 1020002 (in 1999 it was 826036 ). This increase has arisen not merely through personal deterioration in health but also because social adaptation has become more difficult.

In the past decade, a significant number of psychologists, psychotherapists, specialists in social work and social workers have been incorporated into the staff of psychiatric institutions, which has created a basis for transition from a largely medical to a biopsychosocial model of mental healthcare and a team approach to its provision (Table 3 ).

In some regions mental health services have begun to give greater emphasis to care in the community, where a system of psychosocial rehabilitation is organised, hostels and other types of protected housing are set up, interaction with social services is developed, assertive treatment departments (teams) are set up, and 'hospital at home', employment, psychoeducation and psychosocial work with families are provided (Gurovich \& Neufeldt, 2007). Non-governmental organisations (NGOs) are becoming more involved in mental health assistance, although not yet sufficiently so.

Table 3 Numbers of specialists providing psychiatric care

\begin{tabular}{lrr}
\hline Specialists & 1999 & 2008 \\
$\begin{array}{l}\text { Psychiatrists (including } \\
\text { psychotherapists) }\end{array}$ & 15860 & 16184 \\
$\begin{array}{l}\text { Psychotherapists (included in total } \\
\text { above) }\end{array}$ & 3248 & 3438 \\
$\begin{array}{l}\text { Narcologists (specialists providing } \\
\text { care for people with alcohol or } \\
\text { other substance misuse) }\end{array}$ & 4470 & 5329 \\
$\begin{array}{l}\text { Specialists in social work (with } \\
\text { higher education) }\end{array}$ & 70 & 772 \\
$\begin{array}{l}\text { Social workers } \\
\text { Clinical psychologists (in psychiatric } \\
\text { and narcological institutions) }\end{array}$ & 840 & 1857 \\
& 1407 & 3652 \\
\hline
\end{tabular}

\section{Legislation and patients' rights}

The Law on Psychiatric Care, adopted in 1992, works successfully enough at both federal and regional levels, and generally provides for patients' rights. However, social care services and guarantees regarding the provision of mental healthcare have not been implemented sufficiently.

Although there have been some notable omissions and errors in routine clinical practice in recent years (like the nationally well known Rakevich and Arap cases), these have not involved a deliberate violation of patients' rights. In some cases, especially connected with hospitalisation, mental health specialists do not pay enough attention to accounting for their actions to patients and relatives. It is not a matter of violation of the legislation, but rather a question of professional ethics. All such cases or conflicts in psychiatric care are discussed at meetings of the Russian Society of Psychiatrists and in professional journals.

\section{Research}

Because of the urgent need for reform in mental healthcare, Russian psychiatrists consider applied clinical/organisational studies to be the main scientific task in their work. Epidemiology, the formation and trials of new models, new approaches to treatment and rehabilitation on the basis of multiprofessional teamwork, with the involvement of NGOs, are the priority for most researchers and research groups.

The detection and treatment of depressive and anxiety disorders at primary level is also one of the important directions for research, alongside investigating optimal forms of multidisciplinary work and joint research with doctors, cardiologists, neurologists and other specialists (Smoulevich et al, 2005; Krasnov, 2008).

Socially oriented studies have been supported by a special federal programme. Studying the mental health of populations living for a long time under the strain of an emergency situation and then under reconstruction and reconciliation processes, as has been the case in the Chechen Republic (Idrissov \& Krasnov, 2009), is supporting the development of appropriate mental healthcare in specific regions.

Recently, new branches of research and practical psychiatry have emerged in Russia, such as ecological psychiatry and ethnocultural aspects of mental health (Krasnov \& Gurovich, 2007).

\section{Education in psychiatry}

Postgraduate education for clinical practice (after 6 years of formal medical education) comprises an additional 2year course termed 'ordinature' and then 500 hours of specialisation in forensic psychiatry, narcology or psychotherapy (psychotherapy is possible only after at least 3 years of practical work in psychiatry). There are also courses on psychogeriatrics, child psychiatry, psychosomatics and the organisation of psychiatric services. All doctors have to validate their professional status in certificate confirmation courses, once every 5 years.

There is also a variety of training schemes for clinical psychologists and social workers. 


\section{References}

Gurovich, I. Ya. \& Neufeldt, A. H. (eds) (2007) Current Trends and New Service Models in Mental Healthcare. Medpractica-M. (In Russian.)

Idrissov, K. A. \& Krasnov, V. N. (2009) Mental health of the population of the Chechen Republic: a dynamic population 2002-2008 study. Zhurnal nevrologii i psikhiatrii, 109, 76-81. (In Russian.)

Koshkin, A. V. (2009) Prevalence of alcoholism in Russia in 2008. First Russian National Congress on Narcology, November 24-27. Proceedings, Moscow (ed. N. N. Ivanets), pp. 237-238. NNC Narkologii. (In Russian.) Koshkina, E. A. (2009) Substance abuses in modern Russia. First Russian National Congress on Narcology, November 24-27. Proceedings,
Moscow (ed. N. N. Ivanets), pp. 236-237. NNC Narkologii. (In Russian.)

Krasnov, V. N. (ed.) (2008) Improvement of Early Diagnostics of Mental Disorders (on the Basis of Interrelationship with Primary Care Specialists). Medpracitca-M. (In Russian.)

Krasnov, V. N. \& Gurovich, I. Y. (2007) Russian culture and psychiatry. In Culture and Mental Health (eds K. Bhui \& D. Bhugra), pp. 109-121. London: Hodder Arnold.

Nemtsov, A. V. (2009) Alcohol History of Russia: Newest Period. Librokom. (In Russian.)

Smoulevich, A. B., Syrkin, A. L., Drobijev, M. Y., et al (2005) Psychocardiology. Mental Informational Agency. (In Russian.)

\title{
Mental health in the Democratic Republic of Congo: a post-crisis country challenge
}

\section{Michel Okitapoy On'okoko, ${ }^{1,3}$ Rachel Jenkins, ${ }^{2}$ Samuel Mampunza Ma Miezi, ${ }^{3}$ Daniel Okitundu Luwa E Andjafono ${ }^{3}$ and Ildephonse Muteba Mushidi ${ }^{3}$}

\author{
${ }^{1}$ Social and Transcultural Psychiatry, McGill University, Montreal, Canada, email michel.okitapoy@mail.mcgill.ca
} 2Institute of Psychiatry, King's College London, UK ${ }^{3}$ Psychiatry Department, School of Medicine, University of Kinshasa, Democratic Republic of Congo

hep he delivery of mental healthcare in the Democratic Republic of Congo (DRC), formerly Zaire, is influenced by geography, politics, legislation and the structure of the health system, as well as traditional beliefs and culture.

The DRC is in Central Africa; the Central African Republic and Sudan border to the north, Uganda, Rwanda and Burundi to the east, Zambia and Angola to the south, and the Republic of Congo to the west; and it is separated from Tanzania by Lake Tanganyika to the east. The country occupies $2345408 \mathrm{~km}^{2}$, which is slightly greater than Spain, France, Germany, Sweden and Norway combined. For administrative purposes the country is divided into 11 provinces, each with a provincial headquarters.

The population is over 66 million, with $47 \%$ aged under 15 years and $4 \%$ over 60 . Average life expectancy at birth is 46 years for men and 49 years for women. There are around 350 ethnic groups; the largest groups are the Kongo, Luba and Mongo peoples. There are also around 600000 Pygmies, the aboriginal people of the DRC. Although some 700 local languages and dialects are spoken, there is widespread use of French (the official language); the most common local languages are Kongo, Tshiluba, Swahili and Lingala. Eighty per cent of the population are Christian, 10\% Muslim and $10 \%$ follow traditional beliefs or syncretic sects (Central Intelligence Agency, 2008).

Before independence in 1960, the DRC was under Belgian colonial rule. The economy, despite the country's vast natural resources, has greatly declined since the mid-1980s. Recent conflicts, which began in 1996, have dramatically reduced national output and government revenue and increased the external debt, as well as resulting in famine and disease and 5 million conflict-related deaths (US State Department, 2009).
Despite a current lull in overall violence, the plight of people across the eastern DRC remains dire. Thousands have been displaced following renewed violence or rumours of impending violence. Achieving mental health for the population of the DRC is a priority for its economic recovery, achievement of physical health goals and creating resilience among the local people.

\section{Mental health policy and legislation}

The DRC's mental health policy was formulated in 1999. Its essential components are advocacy, promotion, prevention, treatment, rehabilitation and education; there is also a substance misuse policy. The national mental health programme was also formulated in 1999 (World Health Organization, 2005). The Ministry of Health is responsible for the organisation, management and planning of mental health sectors, and it is represented at provincial, district and community level.

The DRC has ratified the international legal instruments concerning the rights and protection of people who are mentally ill, but there is as yet no DRC law defining the rights and protection of people with mental illness or regulating the procedures for voluntary or involuntary admission to a psychiatric hospital.

\section{Mental disorders in the DRC}

Popular beliefs persist about supernatural causes of disease in general and psychiatric problems in particular (Okitapoy, 1993; Okitapoy et al, 1996). 